Subscriber access provided by King Abdullah University of Science and Technology Library

\title{
Sustainability Engineering and Green Chemistry
}

\section{Harvesting Water from Air: Using Anhydrous Salt with Sunlight}

\author{
Renyuan Li, Yusuf Shi, Le Shi, Mossab. Alsaedi, and Peng Wang
}

Environ. Sci. Technol., Just Accepted Manuscript • DOI: 10.1021/acs.est.7b06373 • Publication Date (Web): 02 Apr 2018

Downloaded from http://pubs.acs.org on April 10, 2018

\section{Just Accepted}

"Just Accepted" manuscripts have been peer-reviewed and accepted for publication. They are posted online prior to technical editing, formatting for publication and author proofing. The American Chemical Society provides "Just Accepted" as a service to the research community to expedite the dissemination of scientific material as soon as possible after acceptance. "Just Accepted" manuscripts appear in full in PDF format accompanied by an HTML abstract. "Just Accepted" manuscripts have been fully peer reviewed, but should not be considered the official version of record. They are citable by the Digital Object Identifier (DOI®). "Just Accepted" is an optional service offered to authors. Therefore, the "Just Accepted" Web site may not include all articles that will be published in the journal. After a manuscript is technically edited and formatted, it will be removed from the "Just Accepted" Web site and published as an ASAP article. Note that technical editing may introduce minor changes to the manuscript text and/or graphics which could affect content, and all legal disclaimers and ethical guidelines that apply to the journal pertain. ACS cannot be held responsible for errors or consequences arising from the use of information contained in these "Just Accepted" manuscripts. 


\title{
1 Harvesting Water from Air: Using Anhydrous Salt with Sunlight
}

2
Renyuan Li, Yusuf Shi, Le Shi, Mossab Alsaedi, Peng Wang*

Water Desalination and Reuse Center, Division of Biological and Environmental Science and Engineering, King Abdullah University of Science and Technology, Thuwal 23955-6900, Saudi

Arabia

* Address correspondence to peng.wang@kaust.edu.sa

\begin{abstract}
Atmospheric water is abundant alternative water resource, equivalent to 6 times of water in all rivers on Earth. This work screens 14 common anhydrous and hydrated salt couples in terms of their physical and chemical stability, water vapor harvesting and release capacity under relevant application scenarios. Among the salts screened, copper chloride $\left(\mathrm{CuCl}_{2}\right)$, copper sulfate $\left(\mathrm{CuSO}_{4}\right)$ and magnesium sulfate $\left(\mathrm{MgSO}_{4}\right)$ distinguish themselves and are further made into bi-layer water collection devices, with the top layer being photothermal layer while the bottom layer being saltloaded fibrous membrane. The water collection devices are capable of capturing water vapor out of the air with low relative humidity (down to $15 \%$ ) and releasing water under regular and even weakened sunlight (i.e. $0.7 \mathrm{~kW} / \mathrm{m}^{2}$ ). The work shines light on the potential use of anhydrous salt towards producing drinking water in water scarce regions.
\end{abstract}

\section{Introduction}

In areas neither close to any surface water or sea nor having groundwater conditions, the communities have no choices but typically to rely on very uneconomical long distance transportation of fresh water. ${ }^{1-7}$ On the other hand, there is always plenty of water available in the atmosphere even in very dry desert regions and the atmospheric water, consisting of water vapor and water droplets, is a resource equivalent to $\sim 10 \%$ of all fresh water in lakes and is 6 times all water in rivers on Earth. ${ }^{8}$ As a matter of fact, capturing atmospheric water droplets, or fog, has being operated in remote villages in more than 25 countries worldwide now. ${ }^{9-13}$ However, the fog harvesting necessitates consistently high (typically 100\%) relative humidity $(\mathrm{RH})$ in air, which makes it a viable solution only in a few places, such as western Mediterranean basin and South Africa, and restrains its application from most other regions. ${ }^{14-15}$ While, in the places where harvesting atmospheric water is a necessity, there is typically low RH year-around and thus harvesting water vapor from air with a low RH is a more meaningful and globally relevant task than fog harvesting. ${ }^{16}$

The efforts to harvest water vapor out of low RH air and subsequently to deliver water with an easily accessible and self-sustained energy source had been met with a very limited success. ${ }^{17,18}$ 
In 2017, Yaghi and Wang et al. demonstrated a porous metal-organic framework (MOF) based device that was able to capture water vapor from the ambient air with $\mathrm{RH}$ as low as $20 \%$ and to deliver water using low-grade heat from natural sunlight below one sun $\left(1 \mathrm{~kW} / \mathrm{m}^{2}\right)$ assisted by photothermal materials. ${ }^{19}$ This work stimulates research efforts towards developing more costeffective water absorbents that work with even lower RH.

In light of the application scenario here, a minimum absorption heat is calculated to be higher than $60 \mathrm{~kJ} / \mathrm{mol}$ by using classic Clausius-Clapeyron equation, which falls into chemical absorption range and thus disqualifies such physical adsorption based conventional desiccants as silica gel, ${ }^{20}$ zeolites. ${ }^{21-23}$ The details of the calculation is presented in Supporting Information (SI). In searching for suitable water adsorbents that fulfill the requirements, our attention is attracted by a well-known group of chemicals: hydrated salts and especially their dry and anhydrous counterparts. The anhydrous salts, which are inexpensive and widely commercially available, can absorb air water vapor to become hydrated and have been well utilized in trace water removal from organic solvent. Unlike the conventional desiccants, the uptake of water vapor by the anhydrous salts is a chemical process, known as hydration reaction with absorption heat desirably higher than $60 \mathrm{~kJ} / \mathrm{mol}^{19,22}$

This work aims at providing a proof of concept of using anhydrous and hydrated salt couples to harvest water vapor from very dry ambient air and subsequently to deliver fresh liquid water using sunlight as a sole energy source. In doing so, this work screens 14 common anhydrous and hydrated salt couples and rationally fabricates all-in-one and bi-layered composite disk devices for integrated water vapor collection and photothermal-assisted water release. Among all of the salt couples investigated, copper chloride $\left(\mathrm{CuCl}_{2}\right)$, copper sulfate $\left(\mathrm{CuSO}_{4}\right)$ and magnesium sulfate $\left(\mathrm{MgSO}_{4}\right)$ stand out due to their water absorption/release capability, chemical and physical stability. The results of this work indicate that $\mathrm{CuCl}_{2}$ works better in the regions with low ambient $\mathrm{RH}$ but abundant sunlight irradiation, such as deserts while $\mathrm{CuSO}_{4}$ and $\mathrm{MgSO}_{4}$ are more suitable in the regions with high humidity but low sunlight irradiation such as island or mountain areas. This work shines light on the use anhydrous salts as cost-effective water absorbents towards producing drinking water in water scarce regions.

\section{Material and Methods}

Chemicals and materials. 14 salts, including iron(III) chloride, zinc nitrate, copper (II) nitrate, calcium chloride, nickel(II) nitrate, iron (III) nitrate, iron (II) sulfate, lithium sulfate, sodium carbonate, sodium sulfate, copper(II) chloride, nickel (II) acetate, copper (II) sulfate and magnesium sulfate, were investigated in this work. All salts were purchased from Sigma-Aldrich and used as received. In screening the salts, $2.5 \mathrm{~g}$ of the salts were put into petri dishes of $4.7 \mathrm{~cm}$ in diameter and let sit in ambient air $\left(22{ }^{\circ} \mathrm{C}, 60 \% \mathrm{RH}\right)$ for 24 hours to be fully hydrated. The weight and physicochemical changes of the salts were monitored.

Material characterization. Water vapor absorption and desorption tests were conducted on a Jupiter $^{\circledR}$ simultaneous thermal analyzer (STA) 449 measurement system coupled with water vapor generator. For the dynamic RH test, the water vapor generator was programmed to output nitrogen flow with different $\mathrm{RH}$ along with variable equilibration time. The STA furnace was 
first heated up to $85{ }^{\circ} \mathrm{C}$ and maintained for 4 hours with a constant $\mathrm{RH}$ of $1.5 \%$ for dehydration purpose. After dehydration of the salt samples, the STA furnace was then cooled down to $24{ }^{\circ} \mathrm{C}$ for hydration. During hydration, the system RH was increased step by step from 1.5 to $9 \%$, with a step interval of $1.5 \%$ and equilibration time for each step of $60 \mathrm{~min}$. For the RH range between 9 and $21 \%$, the step interval was $3 \%$ and equilibration time was 30 min while for the RH range between 21 and $80 \%$, the step interval was $6 \%$ with an equilibration time of 30 min for each step. For the static RH test, the water vapor generator was programmed to output nitrogen flow with static RH and a constant equilibration time of 17 hours was employed.

The UV-Vis-NIR spectra were obtained using an Agilent Cary 5000 UV-vis-NIR spectrophotometer and the metal content in the condensed water was examined by inductively coupled plasma-optical emission spectroscopy (ICP-OES) (Optima 8300, PerkinElmer, Inc.) equipped with a Segmented-array-Charge-coupled Device (SCD) detector. Scanning electron microscopy (SEM) images were obtained by FEI Quanta 600 microscope.

Fabrication of bi-layered water collection device. An aliquot of $3.0 \mathrm{~g}$ of as-purchased CNT (Sigma-Aldrich) with a dimension of 6-9 $\mathrm{nm}$ in diameter and $5 \mu \mathrm{m}$ in length was dispersed in a mixture of $90 \mathrm{~mL}$ of $97 \%$ sulfuric acid and $30 \mathrm{~mL}$ of $70 \%$ nitric acid. After refluxed at $70{ }^{\circ} \mathrm{C}$ for 4 hours followed by $2 \mathrm{~h}$ sonication, the as-treated dispersion was filtrated and washed by DI water thoroughly before use.

Disk shaped silica fibrous filter (Whatman ${ }^{\mathrm{TM}}$ ) with a diameter of $47 \mathrm{~mm}$ was employed as substrate. The filter disk was immersed into the solution of the selected salts and the saltsaturated filter disk was dried at $65{ }^{\circ} \mathrm{C}$ for $5 \mathrm{~h}$ to evaporate water. By repeating solution immersion-drying process, mass loading of the hydrated salt in the same substrate was further increased. A layer of the CNT dispersion containing $2 \mathrm{mg}$ of CNT was then painted directly on the top surface of the disk and dried at $65^{\circ} \mathrm{C}$.

Water collection and photothermal assisted water release. The fabricated water collection disk was first exposed to $60 \% \mathrm{RH}$ atmosphere for $24 \mathrm{~h}$ at room temperature (RT) to achieve maximum water absorption capacity. For water releasing test, the hydrated disk was exposed directly under simulated sunlight (Oriel solar simulator) at an intensity of one sun $\left(1 \mathrm{~kW} / \mathrm{m}^{2}\right)$ or lower. The mass change of the disk was monitored and recorded, and the temperature of the disk top surface was measured by an IR camera. In examining the stability of the devices of $\mathrm{CuCl}_{2}$, $\mathrm{CuSO}_{4}$ and $\mathrm{MgSO}_{4}$, the water absorption under ambient conditions $\left(60 \% \mathrm{RH}\right.$ and $\left.22{ }^{\circ} \mathrm{C}\right)$ and photothermal driven water release were repeated for 10 times with the same disk.

\section{Results and Discussion}

Screening of the salts based on physical and chemical stability and their available water

Based on the calculation using Clausius-Clapeyron equation (SI), the work selects 14 commonly available and low-cost salts, all with the water absorption heat $>80 \mathrm{~kJ} / \mathrm{mol}$, including iron(III) chloride $\left(\mathrm{FeCl}_{3}\right)$, zinc nitrate $\left(\mathrm{Zn}\left(\mathrm{NO}_{3}\right)_{2}\right)$, copper (II) nitrate $\left(\mathrm{Cu}\left(\mathrm{NO}_{3}\right)_{2}\right)$, calcium chloride 
$\left(\mathrm{CaCl}_{2}\right)$, nickel(II) nitrate $\left(\mathrm{Ni}\left(\mathrm{NO}_{3}\right)_{2}\right)$, iron (III) nitrate $\left(\mathrm{Fe}\left(\mathrm{NO}_{3}\right)_{3}\right)$, iron (II) sulfate $\left(\mathrm{FeSO}_{4}\right)$, lithium sulfate $\left(\mathrm{Li}_{2} \mathrm{SO}_{4}\right)$, sodium carbonate $\left(\mathrm{Na}_{2} \mathrm{CO}_{3}\right)$, sodium sulfate $\left(\mathrm{Na}_{2} \mathrm{SO}_{4}\right)$, copper(II) chloride $\left(\mathrm{CuCl}_{2}\right)$, nickel (II) acetate $\left(\left(\mathrm{CH}_{3} \mathrm{COO}\right)_{2} \mathrm{Ni}\right)$, copper (II) sulfate $\left(\mathrm{CuSO}_{4}\right)$ and magnesium sulfate $\left(\mathrm{MgSO}_{4}\right)$. The hydrated counterparts of the salts are listed in Table $\mathrm{S} 1$ (SI).

As a preliminary screening, equal mass of $2.5 \mathrm{~g}$ of the hydrated salts as received are first exposed in the air with a $60 \% \mathrm{RH}$ at room temperature (RT) of $22{ }^{\circ} \mathrm{C}$ for 24 hours to ensure water absorption saturation, followed by drying them in an $80{ }^{\circ} \mathrm{C}$ oven for 5 hours. The temperature of the oven drying is chosen based on the consideration of the temperatures that the state of the art photothermal materials can potentially produce under one sun. ${ }^{24-26}$

Figure 1 presents weight of the samples after the 24 hours hydration and 5 hours dehydration, respectively. The salts are grouped into two categories: (a) physically stable salts (Figure 1 (a)) and (b) deliquesced salts (Figure 1 (b)). Four nitrate salts and $\mathrm{CaCl}_{2}$ and $\mathrm{FeCl}_{3}$ deliquesce to different extent during $24 \mathrm{~h}$ hydration step. Deliquescence leads to salts being completely dissolved and thus being present in liquid state (Figure S2), which is undesirable for the targeted application in this project. It is worth pointing out that, for $\mathrm{FeSO}_{4}$, even though it contains 7 hydration water molecules, its instability leads to the loss of hydration property after being heated at $80{ }^{\circ} \mathrm{C}$ in air due to the oxidation of $\mathrm{FeSO}_{4}{ }^{27}$ Furthermore, the hydrated $\mathrm{NaSO}_{4}$ and $\mathrm{LiSO}_{4}$ hold their absorbed water very tight and all have little water release at $80{ }^{\circ} \mathrm{C}(\leq 1.0 \%)$. For this reason, these salts are excluded from further consideration in this work.

Among the rest of the salts, the hydrated salts of $\mathrm{CuCl}_{2}, \mathrm{CuSO}_{4}$ and $\mathrm{MgSO}_{4}$ have reasonably high $(>20 \%)$ available water capacity, defined as the \% weight of water per unit mass of the salt that is available for release at elevated temperature (e.g., $80{ }^{\circ} \mathrm{C}$ ). Thus, they are selected as water absorbent candidates for further investigations.
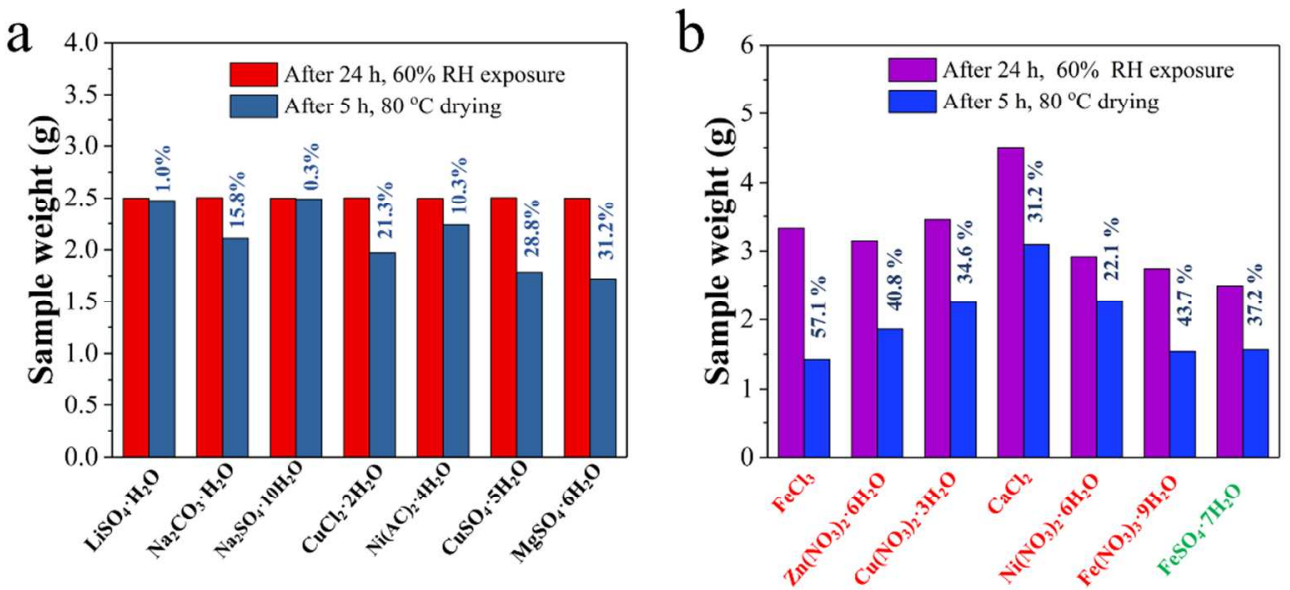

Figure 1. Weight changes of the (a) physical stable salts; (b) deliquesced salts during air hydration and oven dehydration process.

The three selected salts are then subjected to chemical stability assessment. The salts are placed under ambient condition (i.e. $22{ }^{\circ} \mathrm{C}, 60 \% \mathrm{RH}$ ) for 12 hours to ensure a saturated water vapor 
absorption. Then the as-saturated salts (i.e., $\mathrm{CuCl}_{2} \cdot 2 \mathrm{H}_{2} \mathrm{O}, \mathrm{CuSO}_{4} \cdot 5 \mathrm{H}_{2} \mathrm{O}$ and $\mathrm{MgSO}_{4} \cdot 6 \mathrm{H}_{2} \mathrm{O}$ ) are dehydrated at $80{ }^{\circ} \mathrm{C}$ for 2 hours. This hydration and dehydration cycle is repeated for 10 times before XRD analysis being conducted on the hydrated salts in the end. Figure 2 (a) and Figure 2 (b) show the nearly unaltered XRD patterns of the samples before and after 10 cycles of hydration and dehydration for $\mathrm{CuCl}_{2} \cdot 2 \mathrm{H}_{2} \mathrm{O}$ and $\mathrm{CuSO}_{4} \cdot 5 \mathrm{H}_{2} \mathrm{O}$, indicating their high chemical stability. In comparison, the $\mathrm{MgSO}_{4} \cdot 6 \mathrm{H}_{2} \mathrm{O}$ gradually transforms into a mixture of $\mathrm{MgSO}_{4} \cdot 4 \mathrm{H}_{2} \mathrm{O}$ and $\mathrm{MgSO}_{4} \cdot 6 \mathrm{H}_{2} \mathrm{O}$ after 10 cycles (Figure 2 (c)). However, the results show that the available water capacity in this case does not change. ${ }^{28}$

Thermal gravimetric analysis (TGA) is further carried out and, as seen, the onset temperatures of dehydration process are $39.5,32.5$ and $34.5{ }^{\circ} \mathrm{C}$ for $\mathrm{CuCl}_{2} \cdot 2 \mathrm{H}_{2} \mathrm{O}, \mathrm{CuSO}_{4} \cdot 5 \mathrm{H}_{2} \mathrm{O}$ and $\mathrm{MgSO}_{4} \cdot 6 \mathrm{H}_{2} \mathrm{O}$, respectively. For $\mathrm{CuCl}_{2} \cdot 2 \mathrm{H}_{2} \mathrm{O}$, two hydration water molecules are released non-discriminatively, leading to a sharp decrease in its weight along with increasing temperature until $90{ }^{\circ} \mathrm{C}$ when all of the hydration water molecules have been fully released (Figure 2 (d)). For $\mathrm{CuSO}_{4} \cdot 5 \mathrm{H}_{2} \mathrm{O}$, a distinct 3-stage dehydration curve is observed, which corresponds to dehydration from $\mathrm{CuSO}_{4} \cdot 5 \mathrm{H}_{2} \mathrm{O}$ to $\mathrm{CuSO}_{4} \cdot 3 \mathrm{H}_{2} \mathrm{O}\left(32.5{ }^{\circ} \mathrm{C}-63.7{ }^{\circ} \mathrm{C}\right)$ and further to $\mathrm{CuSO}_{4} \cdot \mathrm{H}_{2} \mathrm{O}\left(63.7{ }^{\circ} \mathrm{C}-94.7{ }^{\circ} \mathrm{C}\right)$, and to completely anhydrous $\mathrm{CuSO}_{4}$ at $225.7^{\circ} \mathrm{C}$ (Figure $\left.2(\mathrm{e})\right) .{ }^{29}$

For $\mathrm{MgSO}_{4} \cdot 6 \mathrm{H}_{2} \mathrm{O}, 4$ distinct weight loss stages can be identified, i.e., 34.5 to 71.9, 71.9 to 108.8, 108.8 to 170.8 and 170.8 to $237.8{ }^{\circ} \mathrm{C}$, which correspond to the dehydration of $\mathrm{MgSO}_{4} \cdot 6 \mathrm{H}_{2} \mathrm{O}$ to $\mathrm{MgSO}_{4} \cdot 4 \mathrm{H}_{2} \mathrm{O}, \quad \mathrm{MgSO}_{4} \cdot 4 \mathrm{H}_{2} \mathrm{O}$ to $\mathrm{MgSO}_{4} \cdot 3 \mathrm{H}_{2} \mathrm{O}, \quad \mathrm{MgSO}_{4} \cdot 3 \mathrm{H}_{2} \mathrm{O}$ to $\mathrm{MgSO}_{4} \cdot 1 \mathrm{H}_{2} \mathrm{O}$ and $\mathrm{MgSO}_{4} \cdot 1 \mathrm{H}_{2} \mathrm{O}$ to $\mathrm{MgSO}_{4}$ respectively (Figure 2 (f)). ${ }^{30}$

The TGA results are consistent with those of the $80^{\circ} \mathrm{C}$ oven dehydration (Figure 1) and further confirm that the three salts can release significant amount of their hydration water between 70-85 ${ }^{\circ} \mathrm{C}$, implying they are good candidates for the applications.
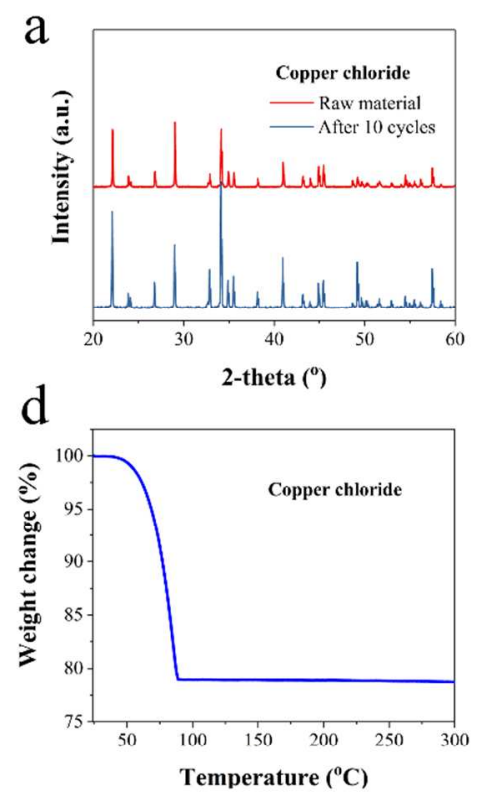

b
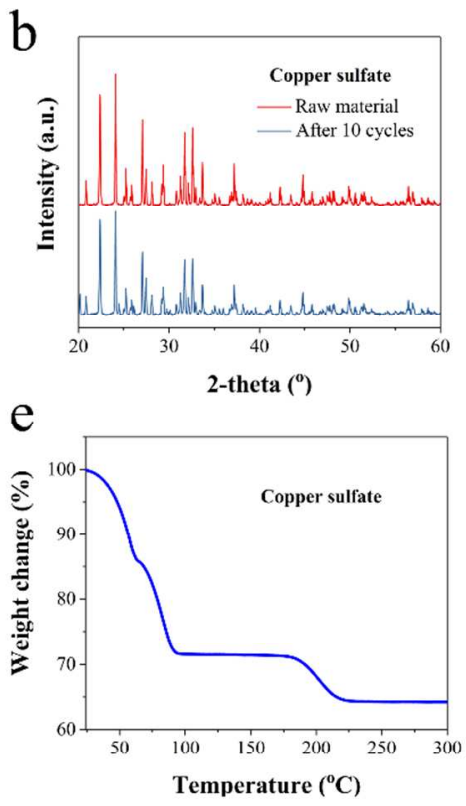
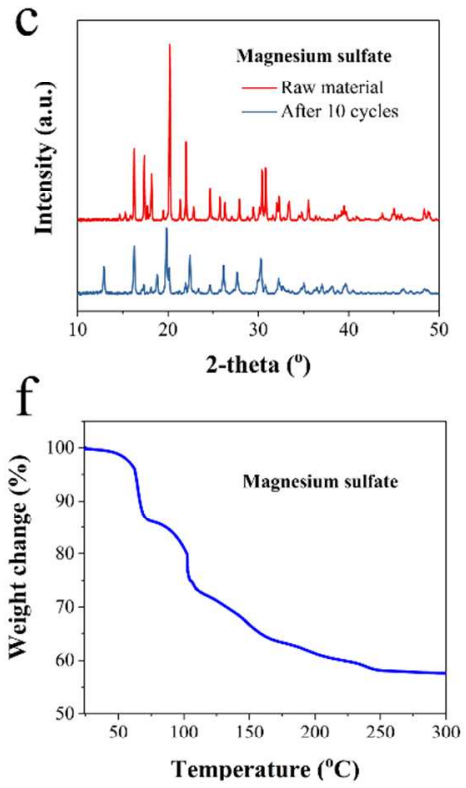
Figure 2. (a)-(c). XRD patterns of $\mathrm{CuCl}_{2} \cdot 2 \mathrm{H}_{2} \mathrm{O}, \mathrm{CuSO}_{4} \cdot 5 \mathrm{H}_{2} \mathrm{O}$ and $\mathrm{MgSO}_{4} \cdot 6 \mathrm{H}_{2} \mathrm{O}$ before and after 10 cycles of hydration and dehydration. TGA curves of (d) $\mathrm{CuCl}_{2} \cdot 2 \mathrm{H}_{2} \mathrm{O}$, (e) $\mathrm{CuSO}_{4} \cdot 5 \mathrm{H}_{2} \mathrm{O}$ and (f) $\mathrm{MgSO}_{4} \cdot 6 \mathrm{H}_{2} \mathrm{O}$. Temperature ranges from 25 to $300{ }^{\circ} \mathrm{C}$, with a ramp of $1{ }^{\circ} \mathrm{C} / \mathrm{min}$.

\section{Water absorption assessment}

172 In order to thoroughly investigate the water vapor absorption property of the three salts, 173 hydration under both dynamic and static RH modes is conducted on a water vapor generator 174 coupled STA. A constant temperature of $24{ }^{\circ} \mathrm{C}$ is chosen and set throughout hydration process in 175 both modes for all samples. The choice of $24{ }^{\circ} \mathrm{C}$ is based on the fact it is a typical temperature in 176 arid areas at night when water vapor absorption takes place. In both modes, the salt samples are 177 thoroughly dehydrated first before conducting water vapor absorption.

178

179

180

181

In the dynamic RH mode, the RH is increased slowly stepwise and at each step equilibrium is obtained by allowing sufficient equilibration time (details regarding the STA steps are provided in SI or method part). In comparison, in the static RH mode the $\mathrm{RH}$ is bumped from $1.5 \%$ directly to a pre-specified value, namely, no RH ramp, and stays there for 17 hours for hydration.
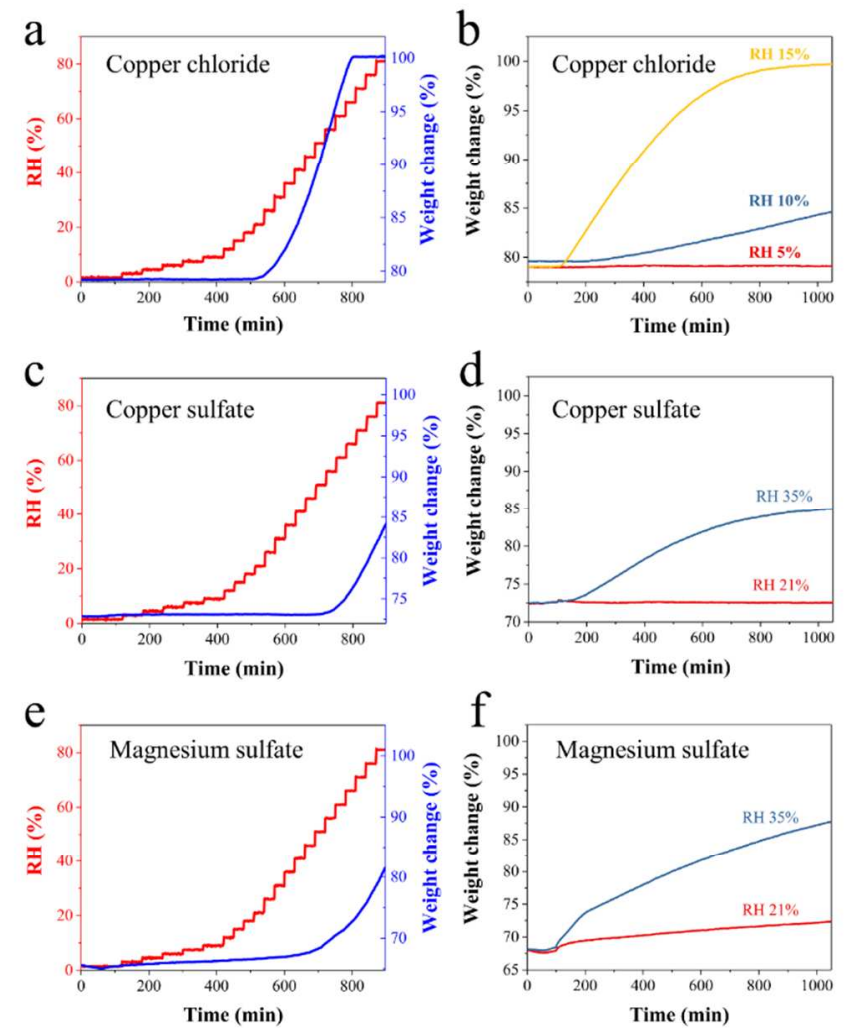

Figure 3. Water vapor absorption curves of $\mathrm{CuCl}_{2}(\mathrm{a}, \mathrm{b}), \mathrm{CuSO}_{4}(\mathrm{c}, \mathrm{d})$, and $\mathrm{MgSO}_{4}(\mathrm{e}, \mathrm{f})$ in dynamic and static RH modes, respectively. 
Figure 3 (a) shows the dynamic $\mathrm{RH}$ hydration result of $\mathrm{CuCl}_{2}$. As seen, the $\mathrm{RH}$ value of its onset water vapor absorption is around $15 \%$ and beyond this point anhydrous $\mathrm{CuCl}_{2}$ quickly reverts to its hydrate state, which is corroborated by the static $\mathrm{RH}$ results (Figure 3 (b)). With a 15\% RH, the $\mathrm{CuCl}_{2}$ salt recovers it full hydration mass from $78 \%$ to $100 \%$. As a matter of fact, anhydrous $\mathrm{CuCl}_{2}$ shows water vapor absorption capability even when the $\mathrm{RH}$ is only $10 \%$, increasing its mass from $78 \%$ to $85 \%$. No hydration is observed for $\mathrm{CuCl}_{2}$ at $\mathrm{RH}$ of $5 \%$. These results indicate that anhydrous $\mathrm{CuCl}_{2}$ is indeed an excellent water absorbent suitable for a very dry air with $\mathrm{RH}$ as low as $10 \%$.

Figure 3 (c) and (d) show that, for anhydrous $\mathrm{CuSO}_{4}$, there is no water absorption at $21 \% \mathrm{RH}$ and the onset water absorption RH is $35 \%$. The high onset absorption RH when combined with its relatively low water release temperature (i.e., $32.5^{\circ} \mathrm{C}$ ) from the TGA (Figure 2 (e)) suggests that anhydrous $\mathrm{CuSO}_{4}$ has low bonding energy with water molecules. ${ }^{29} \mathrm{~A}$ weak absorption energy leads to both a high onset water absorption RH and a low release temperature. Figure 3 (e) and (f) indicate there is no significant water absorption of $\mathrm{MgSO}_{4}$ until $\mathrm{RH}$ is $35 \%$, under which the weight of the salt increases to $87.5 \%$ of its full hydrated weight within the test period.

By comparing the dynamic and static $\mathrm{RH}$ hydration results, it is obvious that the three water absorbent candidates are capable of capturing satisfactory amount of water vapor from the air with different RH and are thus suitable for different application scenarios.

\section{All-in-one water harvesting and release devices}

In light of practical application, a simple device is warranted which integrates in one device both water vapor absorption and water release functions. Given the key nature of water vapor absorption under ambient temperature, water release can be achieved only at higher temperature. Thus, for such a device to work, it has to rely on sunlight to power the water release via means of photothermal effect.

For such a system to be practically applicable and point-of-use, the entire process should standalone without the need of any other additional energy input but the sun, namely, no externally driven heating and cooling. ${ }^{31}$ Moreover, in the step of the absorbed water release, driven by sunlight and assisted by photothermal material, the temperature of the absorbent needs to be raised to $60-85{ }^{\circ} \mathrm{C}$ under one sun irradiation. ${ }^{32-36}$ The captured water is released back to vapor which is then condensed on a collection substrate under ambient conditions. ${ }^{37}$ Given the possibility that there may be no cooler substrate available to aid water condensation, it is desirable that the water vapor being released from the photothermally heated water absorbent has a vapor pressure greater than that of bulk liquid water under the same temperature. This requirement would ideally lead to passive condensation of water vapor where the difference in vapor pressure is the only factor driving water condensation.

Based on these considerations, the device in this work is designed to have bi-layered structure, with the bottom layer being salt-loaded water vapor absorption layer while the top layer being photothermal layer as schematically illustrated in Figure 4. In this work, the device is fabricated 
to have a disk shape. (Structure details of water collection disk can be found in supporting information. Figure S3)

As known, hydrated salts usually are in pulverous state and thus a supporting substrate should be employed to host and keep them in place and to provide mechanical strength and robustness. Silica fibrous filter is selected as substrate due to its low cost, chemical and physical stability. The salt loading is conducted by repeated salt solution immersion followed by oven drying (Figure 4 step 2-3). The fibrous structure of the substrate induces capillary action which leads to uniform distribution of salt solution throughout the entire filter. The amount of water adsorbed by the silica filter is determined to negligible in this work.

CNTs are chosen as photothermal material due to their great light-to-heat conversion efficiency, wide availability and chemical stability. ${ }^{28-40}$ In this work, the as-received CNTs are firstly treated in oxidative acid to make them hydrophilic and the hydrophilic CNTs are then dispersed into DI water to make CNTs ink, which is then simply painted on top of the salt-loaded silica filter substrate as a photothermal layer.
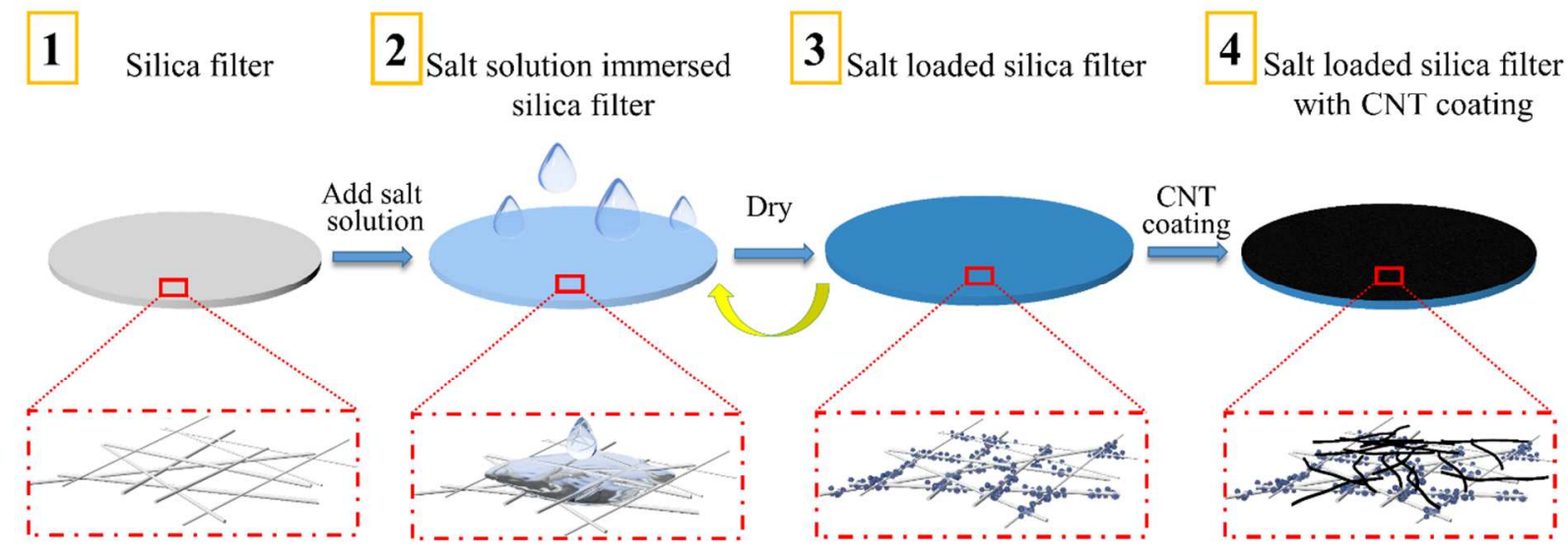

Figure 4. Schematic of water collection disk fabrication process. Step 1, 2, 3, and 4 represent silica fibrous filter substrate, substrate immersion by saturated salt solution, oven drying to evaporate water, and CNT coating process, respectively. Dashed rectangles show the close-up view of the highlighted section in each step.

Figure 5 compares the UV-vis-NIR absorption spectra of the hydrated salt loaded disks with and without the CNT top layer. In the absence of the top CNT layer, the disk of $\mathrm{CuCl}_{2} \cdot 2 \mathrm{H}_{2} \mathrm{O}$ has a higher light absorption than the disk of $\mathrm{CuSO}_{4} \cdot 5 \mathrm{H}_{2} \mathrm{O}$. However, with the top CNT layers, the difference is diminished, with both disks showing dark black colors (Figure 5a and 5b). This is expected given the excellent light absorption capability of the CNTs. For the $\mathrm{MgSO}_{4}$ loaded disk without the top CNT layer, it appears white and has a limited light absorption while the bilayered disk with the CNT layer shows considerably enhanced light absorption and is black (Figure 5c). 

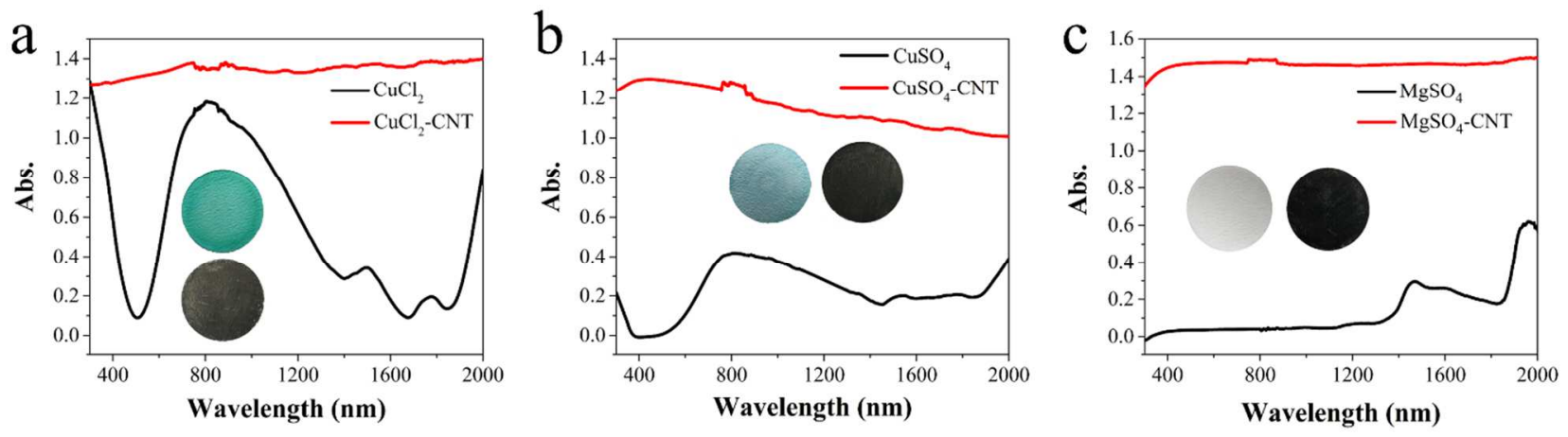

253

254

255

256

257

258

259

260

261

262

263

264

265

266

267

268

269

270

271

272

Figure 5. UV-vis-NIR spectra of (a) $\mathrm{CuCl}_{2}$, (b) $\mathrm{CuSO}_{4}$, and (c) $\mathrm{MgSO}_{4}$ loaded water collection disks before and after coating CNT layer. Insets are the digital images of the water collection disk with or without the CNT top layers.

Figure 6 presents the temperature profiles of the $\mathrm{CuCl}_{2}, \mathrm{CuSO}_{4}$ and $\mathrm{MgSO}_{4}$ loaded silica disks, with and without the top CNT layers. Among all, the $\mathrm{CuCl}_{2}$-based devices show the highest surface temperature, which may be attributed to the much higher light absorbance of $\mathrm{CuCl}_{2}$ than the others (Figure 5). The $\mathrm{CuCl}_{2}$ device without the $\mathrm{CNT}$ layer achieves around $65^{\circ} \mathrm{C}$ after $200 \mathrm{~s}$ under one sun irradiation $\left(1 \mathrm{~kW} / \mathrm{m}^{2}\right)$ while with the top photothermal CNT layer, the surface temperature of the $\mathrm{CuCl}_{2}$ device can be further increased to $75^{\circ} \mathrm{C}$ during the same time period.

Unlike $\mathrm{CuCl}_{2}$, the devices of both $\mathrm{CuSO}_{4}$ and $\mathrm{MgSO}_{4}$ show lower temperatures than $\mathrm{CuCl}_{2}$ (Figure 6 (b) and (c)) due to their weaker light absorbance. With the top CNT layer, the equilibrium temperatures of the bi-layered devices of $\mathrm{CuSO}_{4}$ and $\mathrm{MgSO}_{4}$ increase quickly and considerably to $72{ }^{\circ} \mathrm{C}$ and $66{ }^{\circ} \mathrm{C}$ at the end of first $200 \mathrm{~s}$ of one sun irradiation, respectively. It is worth emphasizing that in our experiments, when the measurement system (Figure S5) is surrounded with a paperboard to decrease the influence by the ambient air disturbance, the bilayered devices of $\mathrm{CuCl}_{2}, \mathrm{CuSO}_{4}$ and $\mathrm{MgSO}_{4}$ can reach surface temperatures of 87 and $85{ }^{\circ} \mathrm{C}$ and $84{ }^{\circ} \mathrm{C}$, respectively (Figure 7 (a)). ${ }^{36}$ This result implies a potential means of sheltering the devices to further increase their surface temperatures under solar irradiation in field, which would enhance water release process and potentially expand the choices of water absorbents. 

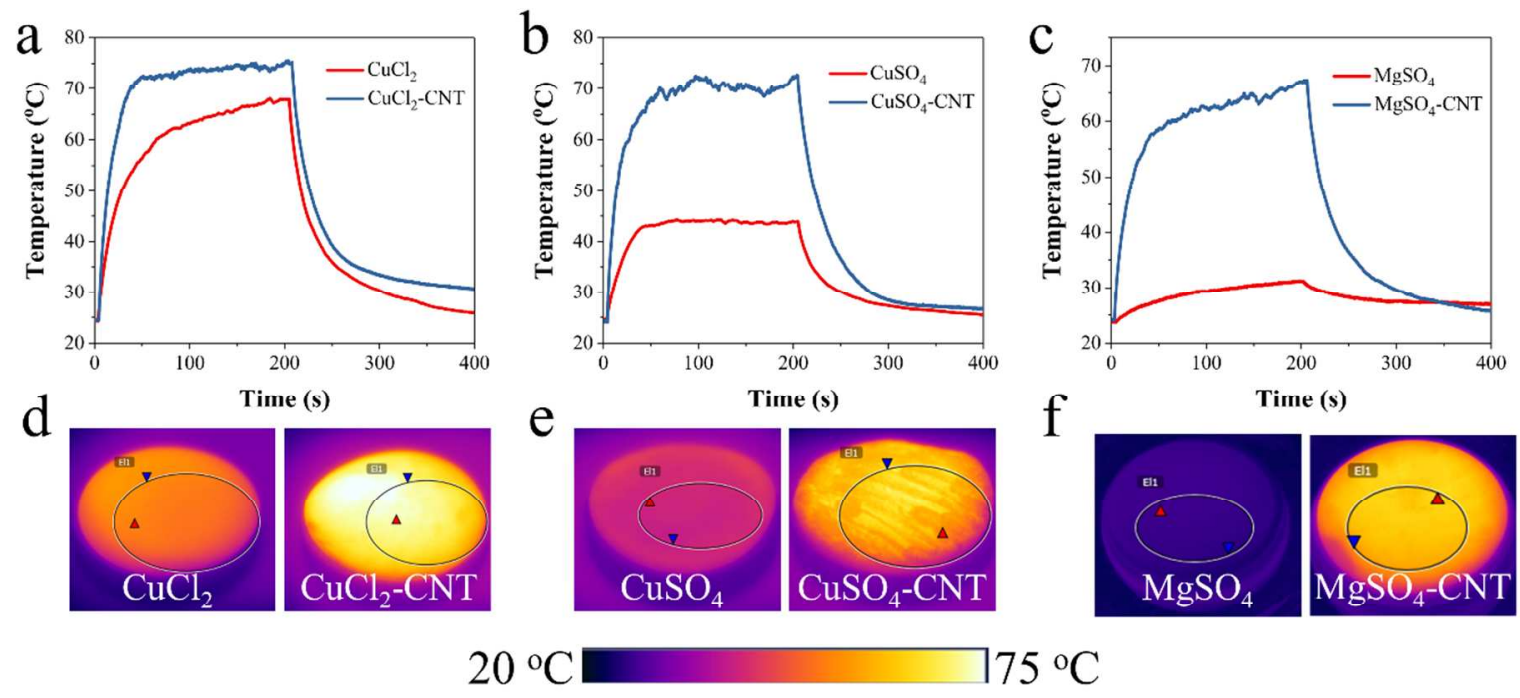

274

275

276

277

278

279

280

281

282

283

284

285

286

287

288

289

290

291

292

293

294

295

296

297

298

299

300

301

The water release behaviors of these devices are then assessed under one sun irradiation. The devices are first exposed to ambient air at $22{ }^{\circ} \mathrm{C}$ and $60 \% \mathrm{RH}$ for more than 24 hours to achieve water vapor absorption equilibrium. The devices are then put onto a polystyrene foam as heat barrier, followed by exposure to one sun irradiation (Figure S5). Figure 7 (b) presents percentage weight change of the bi-layered devices as a function of time under one sun irradiation under ambient RH of $60 \%$ and $22{ }^{\circ} \mathrm{C}$, with the initial weight being the total weight of the fully hydrated salt, silica substrate, and photothermal layers altogether.

Clearly, all devices show fast water release under solar irradiation. For the $\mathrm{CuCl}_{2}$ device, the water release process ends at around $80 \mathrm{~min}$, with $17 \%$ weight loss due to water release. For the $\mathrm{CuSO}_{4}$ device, $21.3 \%$ weight loss is observed by the end of the first $12 \mathrm{~min}$ and an additional $1.7 \%$ is achieved by the end of $25 \mathrm{~min}$. For the $\mathrm{MgSO}_{4}$ device, $26 \%$ weight loss is obtained by $60 \mathrm{~min}$. Table 1 presents $\%$ available water capacity of the three salts and their individual devices. In comparing to the anhydrous salts, the decrease of $\%$ available water capacity in the devices is due to the weight of the fibrous silica substrate and CNT layer, which does not contribute to water absorption capacity. The overall available water capacity of the anhydrous salts and their devices is compatible with the MOF material (i.e. $0.27 \mathrm{~g} / \mathrm{g}$ ) reported recently, indicating the anhydrous salt-based approach has a potential to provide a cost-effective way to harvest water from ambient air. It has to be mentioned that the water collection device used in this test is only a prototype to prove our concept and further improvement will be made to enhance its water collection efficiency. For example, water condensation surfaces/materials with special wettability/structures ${ }^{41-43}$ and high thermal conductivity ${ }^{44}$ would improve water condensation as well as water droplet turnover rates. 
Table 1. Available water of anhydrous salts and their water collection device.

\begin{tabular}{ccc}
\hline & ${\text { Anhydrous salt }(\mathrm{g} / \mathrm{g})^{*}}^{*}$ & $\begin{array}{c}\text { Water collection device }^{\#} \\
(\mathrm{~g} / \mathrm{g})\end{array}$ \\
\hline $\mathrm{CuCl}_{2}$ & 0.27 & 0.21 \\
$\mathrm{CuSO}_{4}$ & 0.40 & 0.30 \\
$\mathrm{MgSO}_{4}$ & 0.45 & 0.35 \\
\hline
\end{tabular}

Note * weight of water released per each gram of anhydrous salt. \# weight of water released per each gram of water collection device.

The water release results indicate successful water release in all three cases under solar irradiation and thus their potentials in practical applications for fresh water production in water scarce regions. While $\mathrm{CuCl}_{2}$ is able to capture water vapor at very low $\mathrm{RH}$, its available water capacity is not as high as the $\mathrm{CuSO}_{4}$ and $\mathrm{MgSO}_{4}$. Among three salts, $\mathrm{MgSO}_{4}$ shows the highest available water capacity, but it requires a high onset absorption RH. These results are consistent with the previous oven dehydration, TGA and STA results.

Given the concern of potential presence of metal ions in the water, we make efforts to measure the concentration of copper in the water samples by using ICP-OES and it turns out that the copper concentrations in the water samples coming from the $\mathrm{CuCl}_{2}$ and $\mathrm{CuSO}_{4}$ water collection disk are both below the detection limit of the instrument (i.e., $0.50 \mathrm{ppb}$ ), which are much lower than the limit of copper in drinking water set by the World Health Organization (WHO) (i.e., $2000 \mathrm{ppb}) .{ }^{45}$ Therefore, there should be no concern in this case.
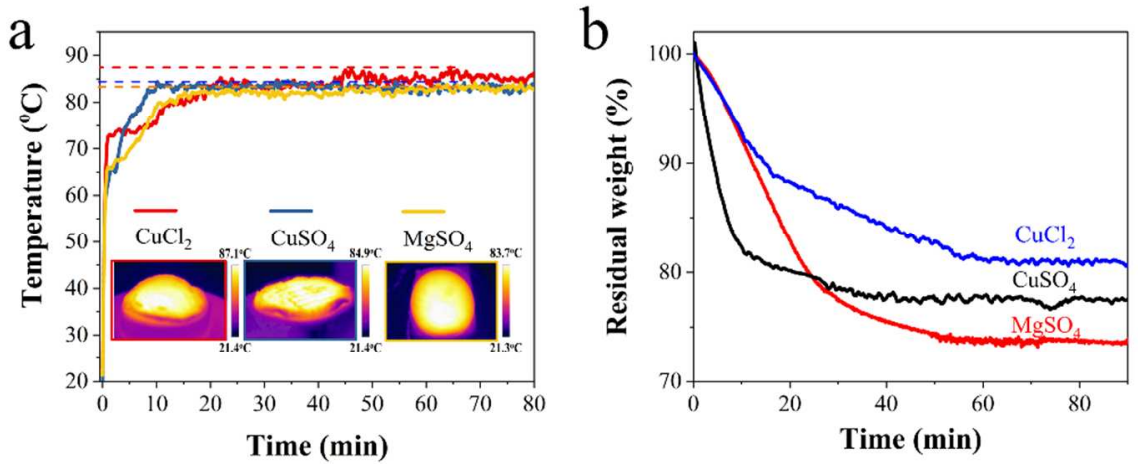

Figure 7. (a) Time course of temperature profile of the devices during solar dehydration conducted with a paperboard shelter. (b) Weight change profile of the bi-layered devices of $\mathrm{CuCl}_{2}, \mathrm{CuSO}_{4}$ and $\mathrm{MgSO}_{4}$ as a function of time under one sun irradiation

Efforts are also made to determine the device performance under weaken sunlight strength (i.e. $0.6,0.7,0.8$, and $0.9 \mathrm{~kW} / \mathrm{m}^{2}$ ). Figure 8 (a) shows a good linear relationships between the light strength and surface temperature of the bi-layered devices while Figures 8 (b)-(d) present time course of water release by the bi-layered devices under light irradiation of different strength.

Significantly, it can be determined from these figures that water release only occurs when the surface temperature is higher than $55^{\circ} \mathrm{C}$ (i.e. light strength $>0.8 \mathrm{~kW} / \mathrm{m}^{2}$ ) for hydrated $\mathrm{CuCl}_{2}$. The 
threshold temperature for hydrated $\mathrm{CuSO}_{4}$ device is $50{ }^{\circ} \mathrm{C}$, corresponding to $0.7 \mathrm{~kW} / \mathrm{m}^{2}$ and beyond the threshold temperature, the water release is quite fast (Figure 8 (c)). For the $\mathrm{MgSO}_{4}$ device, the threshold light intensity for water release is $0.7 \mathrm{~kW} / \mathrm{m}^{2}$, but the water release kinetics shows a strong temperature-dependent behavior (Figure $8(\mathrm{~d})$ ).

These results highlight the importance of light strength in water release. For the $\mathrm{CuCl}_{2}$ device to initiate its water release, it requires a sunlight strength $>0.8 \mathrm{~kW} / \mathrm{m}^{2}$, which is typical in dry and desert regions. For the both $\mathrm{CuSO}_{4}$ and $\mathrm{MgSO}_{4}$ devices, a critical light intensity of 0.7 sun is needed. These results point out that the $\mathrm{CuSO}_{4}$ and $\mathrm{MgSO}_{4}$ devices are more suitable for the regions with higher humidity but weaker sunlight irradiation than those of the $\mathrm{CuCl}_{2}$.

In this project, a water collection device is further fabricated (Figure S6) to demonstrate that the liquid water can indeed be collected and details of the device fabrication and water collection experiment can be found in supporting information.

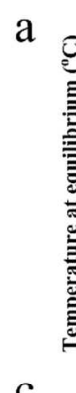

$\mathrm{c}$
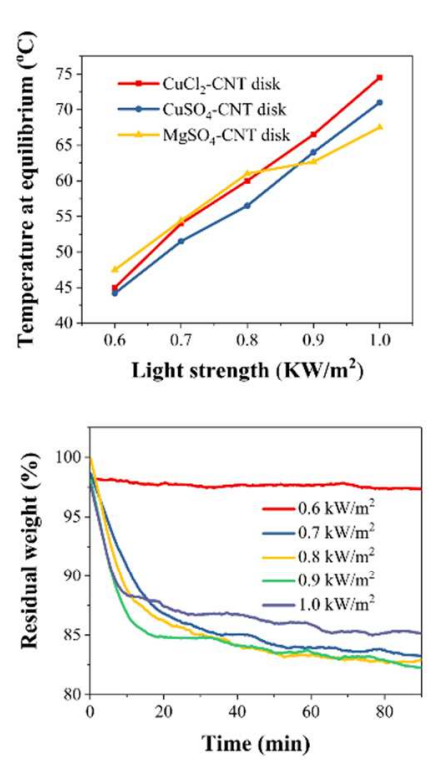

b

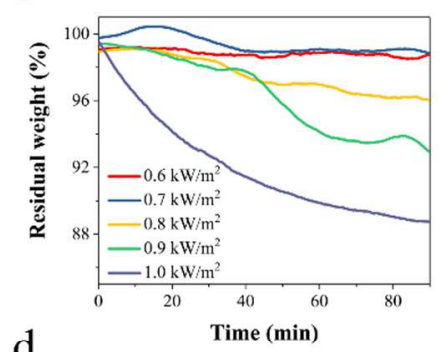

d

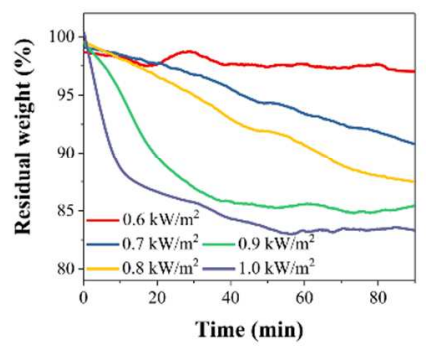

Figure 8. (a) Temperature profiles of the water collection devices under sunlight irradiation of different strength. (b), (c) and (d) photothermal induced water release of (b) $\mathrm{CuCl}_{2}$, (c) $\mathrm{CuSO}_{4}$ and (d) $\mathrm{MgSO}_{4}$ based devices, respectively.

\section{Water collection disk stability test.}

In addition to the previous chemical stability assessment of the salts during 10 cycles of the hydration and dehydration, the stability of the bi-layered devices are further examined. Based on the previous results, the devices of $\mathrm{CuCl}_{2}$ and $\mathrm{CuSO}_{4}$ are exposed at ambient air of $60 \% \mathrm{RH}$ at 22 ${ }^{\circ} \mathrm{C}$ for $5 \mathrm{~h}$ while the one of $\mathrm{MgSO}_{4}$ is exposed for $8.5 \mathrm{~h}$. For dehydration, one sun solar irradiation is set for $1.5 \mathrm{~h}$ uniformly for all devices. The hydration and hydration cycle is repeated for 10 times. 
The overall performance for the three salt devices all maintain at a reasonable level after 10 cycles. For the $\mathrm{CuCl}_{2}$ device(Figure 9 a), the available water capacity after 10 cycles decreases slightly to $92.3 \%$ of the initial capacity before the test while both the $\mathrm{CuSO}_{4}$ and $\mathrm{MgSO}_{4}$ devices maintain their full available water capacities after 10 cycles (Figure $9 \mathrm{~b}$ ).
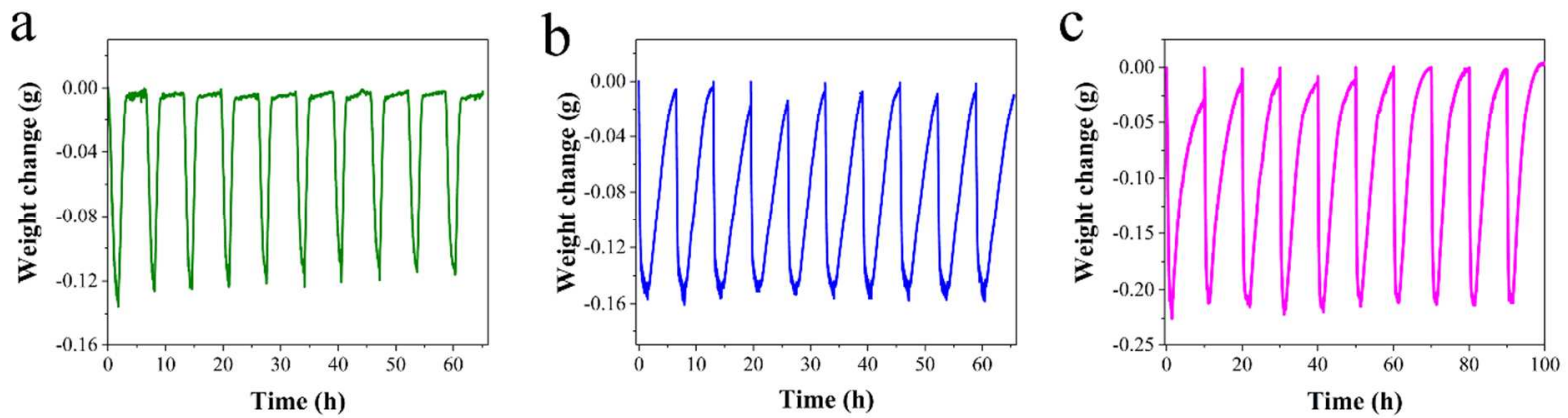

Figure 9: Stability test: Changing of water absorption/desorption performance of (a) $\mathrm{CuCl}_{2}$ and (b) $\mathrm{CuSO}_{4}$ (c) $\mathrm{MgSO}_{4}$ loaded water collection disk. Water releasing section was conducted by simulated sunlight illumination for $1.5 \mathrm{~h}$, followed by water absorption section by turn off the light and exposed to atmosphere for 5 hours $\left(\mathrm{CuCl}_{2}\right.$ and $\left.\mathrm{CuSO}_{4}\right)$ or 8.5 hours $\left(\mathrm{MgSO}_{4}\right)$.

Thus, the results in this work show that anhydrous salts in conjunction with sunlight have a great potential to harvest atmospheric water and supply potable water in water scare regions. More research attentions are warranted to further improve available water capacity of the salts, photothermal energy efficiency, water condensation and liquid water collection performances of the devices.

\section{Acknowledgements}

This work was supported by the King Abdullah University of Science and Technology (KAUST) center competitive fund (CCF) awarded to Water Desalination and Reuse Center (WDRC).

\section{Supporting information:}

1. Table S1. Hydrous/anhydrous couples of the salts used in this work.

2. Discussion on Clausius-Clapeyron equation and minimal adsorption heat calculation

3. Digital photo of salt pre-screening tests

4. Chemistry behind the stage-wise hydration and dehydration of the salts

5. Table S2. Reaction enthalpy of anhydrate salt at different hydration stages

6. Cross-sectional image of $\mathrm{CuCl}_{2}$ water collection disk. Top view $\mathrm{SEM}$ image of $\mathrm{CuCl}_{2}$ water collection disk. 
380 7. UV-vis spectra of the $\mathrm{CuCl}_{2}$ based devices without the top CNT photothermal layer. Digital 381 photo of the $\mathrm{CuCl}_{2}$ based device without the top CNT photothermal layer before and after 382 dehydration.

383 8. Digital photo of homemade solar irradiation-induced water release setup with a paperboard 384 shelter

3859 9. Details on water collection test device.

386

387 


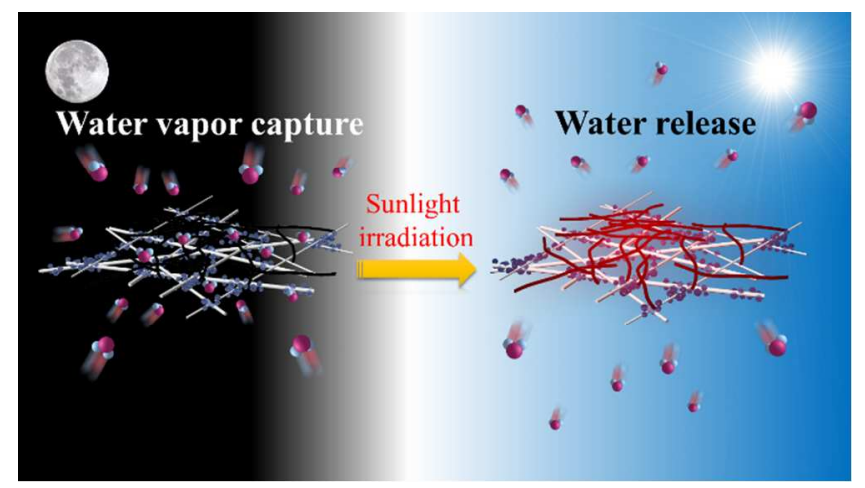




\section{References}

391 1. Mekonnen, M. M.; Hoekstra, A. Y. Four Billion People Facing Severe Water Scarcity. Sci. Adv. 2016, 2 (2). E1500323.

393 2. Schiermeier, Q. Water Risk as World Warms. Nature 2014, 505 (7481), 10-11.

394 3. Montgomery, M. A.; Elimelech, M. Water And Sanitation in Developing Countries: Including 395 Health in the Equation. Environ. Sci. Tech. 2007, 41 (1), 17-24.

396 4. Feng, K.; Hubacek, K.; Pfister, S.; Yu, Y.; Sun, L. Virtual Scarce Water in China. Environ. Sci. Tech. $397 \quad 2014,48(14), 7704-7713$.

$398 \quad 5 . \quad$ (WHO), W. H. O. Water for Health: Taking Charge. 2001.

399 6. WWAP The United Nations World Water Development Report 2015: Water for a Sustainable 400 World. UNESCO 2015.

$4017 . \quad$ Li, R.; Zhang, L.; Wang, P. Rational Design of Nanomaterials for Water Treatment. Nanoscale $402 \quad 2015,7(41), 17167-17194$.

403 8. Stephen H. Schneider; Terry L. Root; Mastrandrea, M. D. Encyclopedia of Climate and Weather 404 (2 ed.). 2011.

405 9. Zhang, L.; Wu, J.; Hedhili, M. N.; Yang, X.; Wang, P. Inkjet Printing for Direct Micropatterning of A 406 Superhydrophobic Surface: Toward Biomimetic Fog Harvesting Surfaces. J. Mater. Chem. A 2015, 3 (6), 407 2844-2852.

408 10. Wang, Y.; Zhang, L.; Wu, J.; Hedhili, M. N.; Wang, P. A Facile Strategy for the Fabrication of A 409 Bioinspired Hydrophilic-Superhydrophobic Patterned Surface for Highly Efficient Fog-harvesting. J.

410 Mater. Chem. A 2015, 3 (37), 18963-18969.

$411 \quad$ 11. Ju, J.; Bai, H.; Zheng, Y.; Zhao, T.; Fang, R.; Jiang, L. A Multi-Structural and Multi-Functional 412 Integrated Fog Collection System in Cactus. Nat. Commun. 2012, 3, 1247-1253.

$413 \quad$ 12. Zheng, Y.; Bai, H.; Huang, Z.; Tian, X.; Nie, F.-Q.; Zhao, Y.; Zhai, J.; Jiang, L. Directional Water 414 Collection on Wetted Spider Silk. Nature 2010, 463, 640-643.

415 13. Kim, G.-T.; Gim, S.-J.; Cho, S.-M.; Koratkar, N.; Oh, I.-K. Wetting-Transparent Graphene Films for 416 Hydrophobic Water-Harvesting Surfaces. Adv. Mater. 2014, 26 (30), 5166-5172.

$417 \quad$ 14. Estrela, M. J.; Valiente, J. A.; Corell, D.; Millán, M. M. Fog Collection in the Western

418 Mediterranean Basin (Valencia region, Spain). Atmos. Res. 2008, 87 (3), 324-337.

419 15. Olivier, J.; de Rautenbach, C. J. The Implementation of Fog Water Collection Systems in South 420 Africa. Atmos. Res. 2002, 64 (1), 227-238.

421 16. McHugh, T. A.; Morrissey, E. M.; Reed, S. C.; Hungate, B. A.; Schwartz, E. Water From Air: An 422 Overlooked Source of Moisture In Arid and Semiarid Regions. Sci. Rep. 2015, 5, 13767-13773.

423 17. Wahlgren, R., V. Atmosphereric Water Vapour Processor Designs for Potable Water Production: 424 A review. Wat. Res. 2001. 35, 1-22.

425 18. Ji, J.; Wang, R.; Li, L. New Composite Adsorbent for Solar-Driven Fresh Water Production from 426 The Atmosphere. Desalination. 2007. 212, 176-182.

$427 \quad$ 19. Kim, H.; Yang, S.; Rao, S. R.; Narayanan, S.; Kapustin, E. A.; Furukawa, H.; Umans, A. S.; Yaghi, O. 428 M.; Wang, E. N. Water Harvesting From Air with Metal-organic Frameworks Powered by Natural Sunlight. 429 Science. 2017, 356, 430-434.

$430 \quad 20 . \quad$ Ng, K. C.; Chua, H. T.; Chung, C. Y.; Loke, C. H.; Kashiwagi, T.; Akisawa, A.; Saha, B. B. Experimental Investigation of the Silica Gel-water Adsorption Isotherm Characteristics. Appl. Therm. Eng. 2001, 21 (16), 1631-1642.

$433 \quad 21 . \quad$ Jentys, A.; Warecka, G.; Derewinski, M.; Lercher, J. A. Adsorption of Water on ZSM 5 Zeolites.

434 The J. Phys. Chem. 1989, 93 (12), 4837-4843. 
22. Furukawa, H.; Gándara, F.; Zhang, Y.-B.; Jiang, J.; Queen, W. L.; Hudson, M. R.; Yaghi, O. M.

Water Adsorption in Porous Metal-Organic Frameworks and Related Materials. J. Am. Chem. Soc. 2014,

438 23. Canivet, J.; Fateeva, A.; Guo, Y.; Coasne, B.; Farrusseng, D. Water Adsorption in MOFs: Fundamentals and Applications. Chem. Soc. Rev. 2014, 43 (16), 5594-5617.

24. Liu, Y.; Yu, S.; Feng, R.; Bernard, A.; Liu, Y.; Zhang, Y.; Duan, H.; Shang, W.; Tao, P.; Song, C.; Deng, T. A Bioinspired, Reusable, Paper-Based System for High-Performance Large-Scale Evaporation. Adv. Mater. 2015, 27 (17), 2768-2774.

$443 \quad 25 . \quad$ Li, X.; Xu, W.; Tang, M.; Zhou, L.; Zhu, B.; Zhu, S.; Zhu, J. Graphene Oxide-based Efficient and 444 Scalable Solar Desalination Under One Sun With A Confined 2D Water Path. P. Natl. Acad. Sci. USA. 2016, $445113(49), 13953-13958$.

446 26. Ito, Y.; Tanabe, Y.; Han, J.; Fujita, T.; Tanigaki, K.; Chen, M. Multifunctional Porous Graphene for High-Efficiency Steam Generation by Heat Localization. Adv. Mater. 2015, 27 (29), 4302-4307.

27. Swamy, M. S. R.; Prasad, T. P.; Sant, B. R., Thermal Analysis of Ferrous Sulphate Heptahydrate in Air. J. Therm. Anal. 1979, 16 (2), 471-478.

28. Donkers, P. A. J.; Beckert, S.; Pel, L.; Stallmach, F.; Steiger, M.; Adan, O. C. G. Water Transport in MgSO4.7H2O During Dehydration in View of Thermal Storage. J. Phys. Chem. C 2015, 119 (52), 2871128720.

29. El-Houte, S.; El-Sayed Ali, M.; Sørensen, O. T. Dehydration of CuSO4 · $5 \mathrm{H} 2 \mathrm{O}$ Studied by Conventional and Advanced Thermal Analysis Techniques. Thermochim. Acta 1989, 138 (1), 107-114.

30. Grevel, K.-D.; Majzlan, J.; Benisek, A.; Dachs, E.; Steiger, M.; Fortes, A. D.; Marler, B. Experimentally Determined Standard Thermodynamic Properties of Synthetic $\mathrm{MgSO}_{4} \cdot 4 \mathrm{H}_{2} \mathrm{O}$ (Starkeyite) and $\mathrm{MgSO}_{4} \cdot 3 \mathrm{H}_{2} \mathrm{O}:$ A Revised Internally Consistent Thermodynamic Data Set for Magnesium Sulfate Hydrates. Astrobiology 2012, 12 (11), 1042-1054.

459 31. Jackson, R. D.; Van Bavel, C. H. M. Solar Distillation of Water from Soil and Plant Materials: A Simple Desert Survival Technique. Science 1965, 149 (3690), 1377-1379.

32. Neumann, O.; Urban, A. S.; Day, J.; Lal, S.; Nordlander, P.; Halas, N. J. Solar Vapor Generation Enabled by Nanoparticles. ACS Nano 2013, 7 (1), 42-49.

33. Li, R.; Zhang, L.; Shi, L.; Wang, P. MXene $\mathrm{Ti}_{3} \mathrm{C}_{2}$ : An Effective 2D Light-to-Heat Conversion Material. ACS Nano 2017, 11 (4), 3752-3759.

$465 \quad$ 34. Zhang, L.; Tang, B.; Wu, J.; Li, R.; Wang, P. Hydrophobic Light-to-Heat Conversion Membranes with Self-Healing Ability for Interfacial Solar Heating. Adv. Mater. 2015, 27 (33), 4889-4894.

35. Wang, Y.; Zhang, L.; Wang, P. Self-Floating Carbon Nanotube Membrane on Macroporous Silica Substrate for Highly Efficient Solar-Driven Interfacial Water Evaporation. ACS Sustain. Chem. Eng. 2016, 4 (3), 1223-1230.

36. Shi, L.; Wang, Y.; Zhang, L.; Wang, P. Rational Design of A Bi-Layered Reduced Graphene Oxide Film on Polystyrene Foam for Solar-driven Interfacial Water Evaporation. J. Mater. Chem. A 2017, 5 (31), 16212-16219.

37. Jin, Y.; Zhang, L.; Wang, P. Atmospheric Water Harvesting: Role of Surface Wettability and Edge Effect. Global Challenges 2017, 1 (4), 1700019.

38. Markovic, Z. M.; Harhaji-Trajkovic, L. M.; Todorovic-Markovic, B. M.; Kepić, D. P.; Arsikin, K. M.; Jovanović, S. P.; Pantovic, A. C.; Dramićanin, M. D.; Trajkovic, V. S. In Vitro Comparison of the Photothermal Anticancer Activity of Graphene Nanoparticles and Carbon Nanotubes. Biomaterials 2011, 32 (4), 1121-1129.

39. Gannon, C. J.; Cherukuri, P.; Yakobson, B. I.; Cognet, L.; Kanzius, J. S.; Kittrell, C.; Weisman, R. B.; Pasquali, M.; Schmidt, H. K.; Smalley, R. E.; Curley, S. A. Carbon Nanotube-Enhanced Thermal

481 Destruction of Cancer Cells in A Noninvasive Radiofrequency Field. Cancer 2007, 110 (12), 2654-2665. 
482 40. Wang, Y.; Tang, B.; Zhang, S. Single-Walled Carbon Nanotube/Phase Change Material 483 Composites: Sunlight-Driven, Reversible, Form-Stable Phase Transitions for Solar Thermal Energy 484 Storage. Adv. Funct. Mater. 2013, 23 (35), 4354-4360.

485 41. Heng, X.; Xiang, M.; Lu, Z.; Luo, C. Branched ZnO Wire Structures for Water Collection Inspired 486 by Cacti. ACS Appl. Mater. Interfaces. 2014, 6, 8032-8041.

487 42. Andrews, H., G.; Eccles, E., G.; Schofield, W., C., E.; Badyal, J., P., S. Three-dimensional 488 Hierarchical Structures for Fog Harvesting. Langmuir. 2011, 27, 3798-3802.

489 43. Enright, R.; Miljkovic, N.; Al-Obeidi, A.; Thompson, C., V.; Wang, E., N. Condensation on 490 Superhydrophobic Surfaces: The Role of Local Energy Barriers and Structure Length Scale. Langmuir. $4912012,28,14424-14432$.

492 44. Cho, H., J.; Preston, D., J.; Zhu, Y.; Wang, E., N. Nanoengineered Materials for Liquid-vapour 493 Phase-change Heat Transfer. Nat. Rev. Mater. 2016. 2, 16092.

494 45. WHO, Guidelines for Drinking-water Quality (4 ${ }^{\text {th }}$ edition). 2017. 